\title{
Diaphragm Ultrasound As A Method To Predict Ventilation Outcome In Children: The Prospective Observational Cohort Study.
}

\section{O. Filyk, Ya. Pidhirnyy \\ Department of Anesthesiology and Intensive Care Danylo Halytsky Lviv National Medical University Lviv, Ukraine}

\section{Background and Goal of Study}

Diaphragm dysfunction worsens outcomes in mechanically ventilated patients. However, the clinical impact of changes in diaphragm structure and function due to mechanical ventilation (MV) is unknown.

The hypothesis was that in children the duration of $\mathrm{MV}$ and the duration of stay in the intensive care unit, the frequency of complications depend on the degree of diaphragm atrophy. The aim of the study was to determine whether diaphragm atrophy developing during $\mathrm{MV}$ leads to prolonged ventilation.

\section{Materials and Methods}

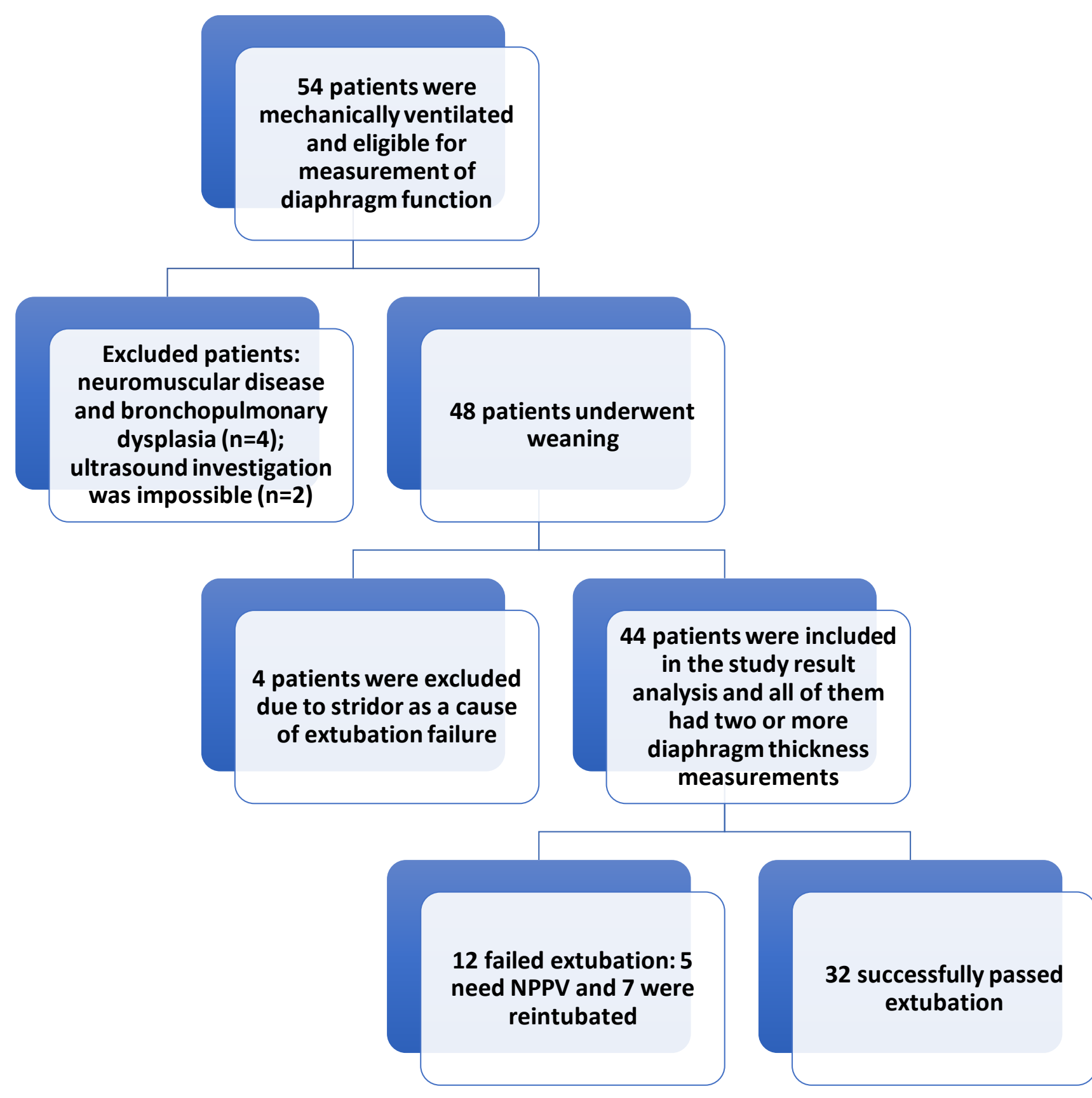

Fig. 1. A flow chart showing criteria of patients' selection and follow up through the study.

Diaphragm thickness (Tdi) at the end of inspiration and diaphragmatic excursion were measured daily by ultrasound in children requiring invasive $\mathrm{MV}$, evaluating an inspiratory effort was assessed by thickening fraction.

The primary outcome was the time to liberation from ventilation. The secondary outcomes included complications (reintubation, tracheostomy, prolonged ventilation, or death). Statistical Package for the Social Sciences was used and results were presented using adjusted hazard ratio (HR), duration ratio, and odds ratio (OR).

\section{Results and Discussion}

Thickness decreased to more than $10 \%$ in 30 patients (63\%) by median day 6 (IQR 5-7).

\subsection{8 times prolonged

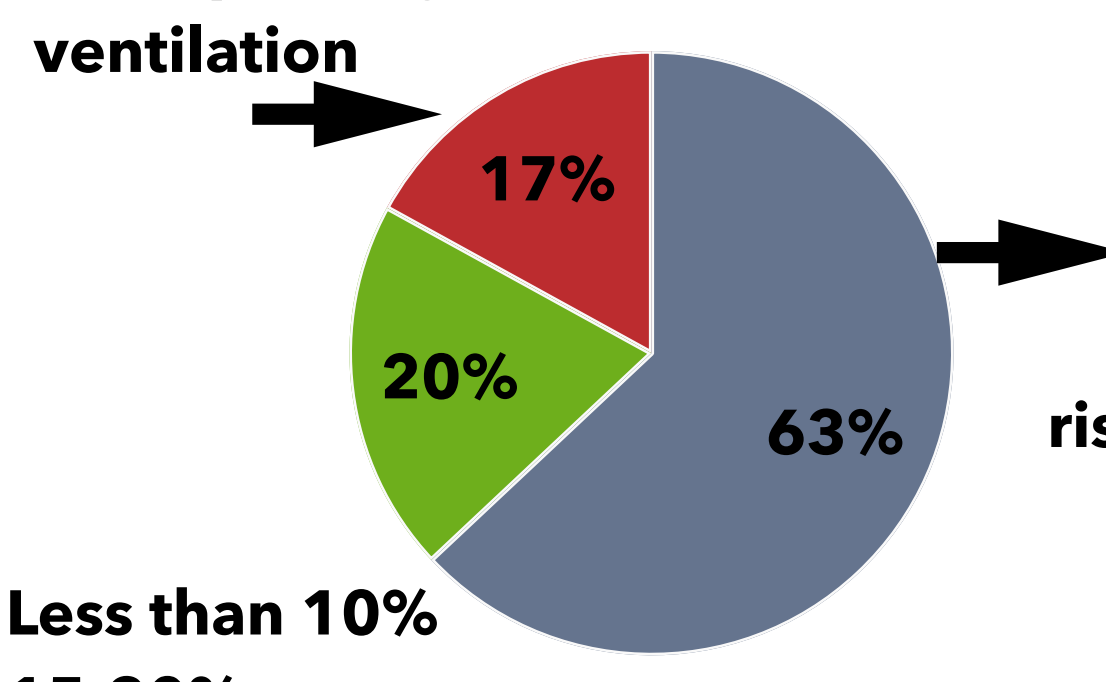 \\ 1.63 times \\ prolonged ICU \\ admission; \\ 2.14 times higher risk of complications. \\ $15-30 \%$ \\ More 30\%}

Fig. 2. Diaphragm thickness (Tdi) at the end of inspiration

The development of decreased thickness was associated with a lower daily probability of liberation from ventilation (adjusted HR 0.47, 95\% Cl 0.38-0.62, per $10 \%$ decrease), prolonged ICU admission (duration ratio $1.63,95 \% \mathrm{Cl} 1.25-2.44$ ), and a higher risk of complications (OR 2.14, 95\% Cl 1.21-4.72). The development of increased thickness $(n=8,17 \%)$ also predicted prolonged ventilation (duration ratio 1.38, $95 \% \mathrm{Cl} 1.00-1.90)$. Decreasing thickness was related to abnormally low inspiratory effort; increasing thickness was related to excessive effort. Patients with thickening fraction between 15-30\% during the first 4 days had the shortest duration of ventilation.

Tabl. 1. Comparison of weaning parameters between patients on 4-th day of weaning $(n=44)$.

\begin{tabular}{|c|c|c|c|}
\hline & 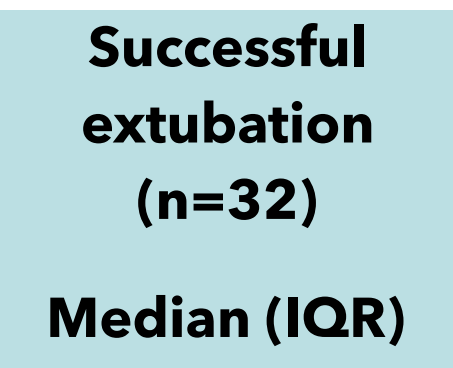 & $\begin{array}{l}\text { Failed extubation } \\
\qquad(\mathrm{n}=12) \\
\text { Median (IQR) }\end{array}$ & P-value \\
\hline $\begin{array}{l}\text { RSBI, breath } / \mathrm{ml} \\
\text { * kg }\end{array}$ & $8.1(7.3-9.2)$ & $13.9(12.4-18.1)$ & 0.06 \\
\hline $\begin{array}{l}\text { TV/body weight, } \\
\mathrm{ml} / \mathrm{kg}\end{array}$ & $6.9(6.5-8.6)$ & $4.3(4.1-5.9)$ & 0.08 \\
\hline RR, breath/min & $32(22-34)$ & $48(38-56)$ & 0.001 \\
\hline $\mathrm{PaO2} / \mathrm{FiO} 2$ & $210(204-358)$ & $182(157-218)$ & 0.05 \\
\hline Diaphragmatic & $9.2(10.4-8.9)$ & $6.5(5.8-7.3)$ & 0.001 \\
\hline
\end{tabular}

\section{Conclusion}

Diaphragm atrophy developing during MV strongly impacts clinical outcomes. 